\title{
An infant with massive haemobilia due to cavernous transformation of the portal vein
}

\author{
M P Senanayake ${ }^{1}$, R Rodrigo $^{2}$, A Lamahewage $^{3}$, S Abeygunasekera ${ }^{3}$ \\ Ceylon Medical Journal 2012; 57: 44-45
}

\section{Introduction}

Haemobilia or bleeding into the biliary tract is a very rare occurrence in children. We report an infant who bled profusely into the biliary tract from dilated pericholecystic veins that were part of a sponge like mass of tortuous, collateral veins replacing the portal vein. This venous anomaly is referred to as cavernous transformation of the portal vein or portal cavernoma and is a sequel of portal vein thrombosis $[1,2]$.

\section{Case report}

A six-month old exclusively breast fed boy developed episodic profuse painless bleeding per rectum. Within first eight hours after admission, six nappies were soaked with fresh blood containing clots. The single episode of vomiting contained coffee ground material. He was not in pain, fed normally and his mother reported that bleeding appeared to be related to feeding. Weaning had not commenced.

He was the fourth child of non-consanguineous healthy parents with no family history of bleeding disorders. Birth and neonatal period were normal. There was no umbilical sepsis, umbilical vein catheterisation or liver disease. Apart from a watery diarrhoea five days prior to this illness which had not needed hospitalisation or intravenous fluids, he had been well until gastro-intestinal bleeding started. On examination he was pale. There was no jaundice or dilated veins on the abdominal wall. Abdomen was soft, not distended and there was no hepatomegaly, splenomegaly or any other lumps.

Rectal bleeding continued in large bouts. Initial platelet count of $139 \times 10^{3} / \mu 1$ dropped to $12 \times 10^{3} / \mu 1$ on the second day. Clotting profile was normal. Intussusception was excluded on ultrasonography. Upper gastro-intestinal endoscopy showed bleeding from ampulla of Vater with no oesophageal or gastric varices, mucosal ulceration or inflammation. Computer tomography (CT) scan showed numerous collateral vessels suggestive of congenital arterio-venous (AV) malformation or cavernous transformation of the portal vein but aorto-angiogram showed normal coeliac axis and superior mesenteric arteries ruling out AV malformation. Splenoportogram showed a multiple sponge like mass of collaterals replacing the portal vein (Figure 1). Doppler studies excluded portal hypertension.

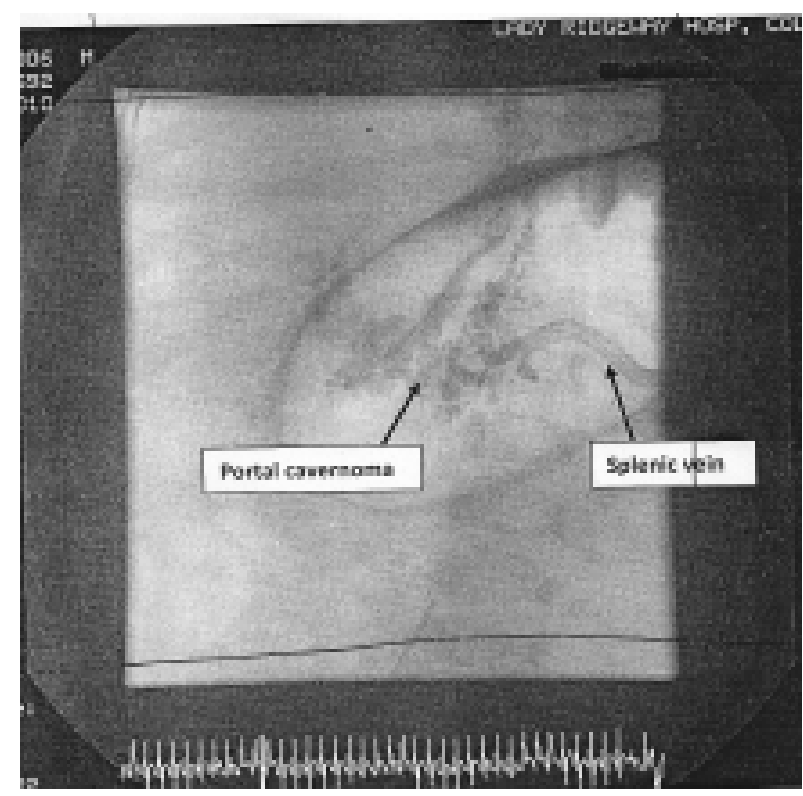

Figure 1. Splenoportogram cavernous transformation of the portal vein (portal cavernoma).

Occlusion of the abnormal veins using an interventional radiological procedure posed difficulties of access and laparotomy was planned. Surgery was not possible until consumptive coagulopathy that followed severe bleeding was corrected. This needed 18 blood transfusions, 17 platelet transfusions and 10 plasma transfusions.

At surgery abnormally dilated venous tributaries instead of a portal vein, a normal splenic vein and spleen were found. A splenorenal shunt which proved to be life saving was performed [3]. He has remained free of bleeding

${ }^{1}$ Department of Paediatrics, Faculty of Medicine, Colombo, Sri Lanka, ${ }^{2}$ Department of Paediatrics, Faculty of Medicine, Kelaniya, Sri Lanka, ${ }^{3}$ Lady Ridgeway Hospital, Colombo, Sri Lanka.

Correspondence: MPS, e-mail : <manouri.senanayake@gmail.com>. Received 13 May and revised version accepted 22 October 2011. Competing interests: none declared. 
for over six months. A hypercoagulable state was excluded with normal protein $\mathrm{C}$ and $\mathrm{S}$ levels and normal genetic studies for Factor V Leiden, prothrombin and methylene tetrahydrofolate reductase deficiency mutations. Lupus anticoagulant was absent and the Ham's test was negative.

\section{Discussion}

Massive haemobilia due to rupture of a portal cavernoma is very rare. In our patient the cause for portal vein thrombosis remains obscure in the absence of umbilical sepsis, severe dehydration or a hypercoaguable state. Cavernous transformation has been documented even within a few days of the portal vein getting obstructed; and inflammation resulting from enteritis is a recognised cause of portal vein thrombosis [4]. However, enteritis is an unlikely explanation for portal vein obstruction in this infant because the diarrhoeal illness was mild and short lasting.

\section{Acknowledgment}

We thank Drs. Nihal Wijewardene and Jerard
Fernando, Consultant Radiologists of National Hospital, Colombo and Lady Ridgeway Children's Hospital (LRH) respectively.

\section{References}

1. Chandra R, Kapoor D, Tharakan A, Chaudary A, Sarin SK. Portal biliopathy. Journal of Gastroenterology and Hepatology 2001; 16: 1086-92.

2. Dhiman RK, Behera A, Chawla YK, Dilawari JB, Suri S. Recent advances in clinical practice - portal hypertensive biliopathy. Gut 2007; 56: 1001-8.

3. Webster GJM, Burroughs AK, Riordan SM. Review article: portal vein thrombosis - new insights into aetiology and management: Alimentary Pharmacology and Therapeutics 2005; $21: 1-9$.

4. De Gaetano AM, Lafortune M, Patriquin H, et al. Cavernous transformation of the portal vein: patterns of intrahepatic and splanchnic collateral circulation detected with Doppler sonography. American Journal of Roentology 1995; 165: 1151-5. 